\title{
Pediatric Intussusception in Northern Iran: Comparison of Recurrent With Non-Recurrent Cases
}

\author{
Mohammad Reza Esmaeili-Dooki, ${ }^{1}$ Leila Moslemi, ${ }^{1, *}$ Abbas Hadipoor, ${ }^{1}$ Soheil Osia, ${ }^{1}$ and \\ Seyed-Abbas Fatemi ${ }^{1}$ \\ ${ }^{1}$ Non-Communicable Pediatric Diseases Research Center, Health Research Institute, Babol University of Medical Sciences, Babol, IR Iran \\ ${ }^{*}$ Corresponding author: Leila Moslemi, Non-Communicable Pediatric Diseases Research Center, Babol University of Medical Sciences, Babol, IR Iran. Tel: +98-911116806, Fax: +98-1132346963, \\ E-mail: leilamoslemi116@yahoo.com
}

Received 2015 August 25; Accepted 2015 November 29.

\begin{abstract}
Background: Intussusception represents as the invagination of a part of the intestine into itself and is the most common cause of intestinal obstruction in infants and children between 6 months to 3-years-old.

Objectives: The objective of this study was to determine the recurrence rate and predisposing factors of recurrent intussusception.

Patients and Methods: The medical records of children aged less than 13-years-old with confirmed intussusception who underwent reduction at a tertiary academic care in northern Iran (Mazandran), from 2001 to 2013 were reviewed. Data were extracted and recurrence rate was determined. The two groups were compared by chi square, Fisher, Mann-Whitney and t-test. Diagnosed cases of intussusception consisted of 237 children.

Results: Average age of the patients was $19.57 \pm 19.43$ months with a peak of 3 to 30 months. Male to female ratio was 1.65 and this increased by aging. Recurrence rate was $16 \%$ (38 cases). 87 (36.7\%) underwent surgery. These were mainly children under one year old. In $71 \%$ (40) of episodes recurrence occurred 1 to 7 times within 6 months. The recurrence occurred in $29(23.5 \%)$ children in whom a first reduction was achieved with barium enema $(\mathrm{BE})$ and $5(5.7 \%)$ children who had an operative reduction $(\mathrm{P}<0.001)$ in the first episode. Pathological leading points (PLPS) were observed in 5 cases; $2.6 \%$ in recurrence group versus $2 \%$ in non-recurrence group $(\mathrm{P}=0.91)$. Three patients had intestinal polyp, 2 patient's lymphoma and Mackle's diverticulum. Age $(\mathrm{P}=0.77)$ and $\operatorname{sex}(\mathrm{P}=0.38)$ showed no difference between the two groups. PLPs were observed in $1.4 \%$ of children aged 3 months to 5 years. This was $13.3 \%$, in older children $(\mathrm{P}=0.02)$.

Conclusions: The recurrence of intussusception was related to the method of treatment in the first episode and it was 5-fold higher in children with BE than in operative reduction. Recurrent intussusceptions were not associated with PLPs, they were more idiopathic.
\end{abstract}

Keywords: Intussusception, Recurrence Rate, Pathologic Lead Point, Operative Reduction, Barium Enema Reduction

\section{Background}

Intussusception represents as the invagination of a part of the intestine into itself and is the most common cause of intestinal obstruction in infants and children between 6 months to 3-years-old (1-3). Although intussusception can occur at any age, it is often observed in population lower than two years old and includes $80-90 \%$ of cases (3). The etiology of most intussusceptions is not known and an identified disease trigger or a pathologic lead point could not be determined in more than $90 \%$ of cases (4-9). The recurrence rate of intussusception is $8 \%$ to $15 \%(10,11)$ and it is observed more in non-surgical reduction than surgical reduction (10). There are controversies about the treatment of recurrent intussusception, some suggested operative intervention after the first and second recurrence, whereas, others recommended each recurrence should be handled as though it was the first episode $(12,13)$ so choice treatment of recurrent intussusception is unknown (10).

\section{Objectives}

The present study aimed to review childhood intussus- ception based on hospital data from referral tertiary pediatric center in North Iran in a 12-years-old period to determine the recurrence rate and compare the recurrence and non-recurrence subjects for recognizing the predisposing factors in childhood recurrent intussusception.

\section{Patients and Methods}

This investigation was a retrospective descriptive study conducted at Amirkola Children's hospital, a tertiary pediatric department, as only referral center in Northern Iran (Mazandran province). The studied cases included children below 13-years-old of age with definite diagnosis of intussusception who were hospitalized and treated from September 2001 to October 2013. Data were extracted from medical records with ICD-9-CM code 560.0. Information collected included gender, age, season of presentation, clinical symptoms and signs, duration of symptoms, recurrent intussusception, method of treatment, and outcome. We analyzed cases of recurrent intussusception to determine predisposing factors for recur-

Copyright (C) 2016, Growth \& Development Research Center. This is an open-access article distributed under the terms of the Creative Commons Attribution-NonCommercial 4.0 International License (http://creativecommons.org/licenses/by-nc/4.0/) which permits copy and redistribute the material just in noncommercial usages, provided the original work is properly cited. 
rence. For data analysis chi square, Fisher, Mann-Whitney and t-test were used. A P $<0.05$ is considered as significant.

\section{Results}

During a 12-year period, from 2001 to 2013, 294 episodes of intussusception were confirmed in 237 patients. Thirty eight from 237 children had more than one episode, so overall recurrence rate was $16 \%$ (38/237). The recurrence rates were $16.4 \%$ (19/116) in children less than one year old, $14.5 \%(10 / 69), 22.2 \%(6 / 27)$ and $12 \%(3 / 25)$ in children 1 to 2,2 to 3 and over 3-years-old respectively. There was no difference in the recurrence rates between male and female children (14.4\% vs. $18.7 \%, \mathrm{P}=0.51)$. Number of recurrences ranged from one to 7 times. The highest number occurred in one boy. He was 7 months old in the first episode and treated by surgical reduction six times and also by barium enema (BE). In recurrent group, interval time for each recurrence was 1 day to 4.9 years. Forty of 56 (71\%) recurrent episodes occurred within six months, 19 (34\%) of which were observed in the first 24 hours (Table 1). BE was successful 72.7\% in the first episode, the recurrence occurred in 29(23.5\%) of reduced cases by BE and in 5 (5.7\%) cases by operative reduction $(\mathrm{P}<0.001)$. Surgery was performed in $36.7 \%$ of patients in the first episode, of whom 5 were of recurrence and 82 of non-recurrence group (11.1\% vs. $40.8 \%, \mathrm{P}=0.005)$. The surgical intervention was done in $47.8 \%$ of infants of less than one year old and $31.7 \%$ of children more than one year old $(\mathrm{P}=0.004)$. The outcome in the four first episodes is shown in Figure 1. In the first episode, the average of duration of symptoms (from presentation to intervention) was $26.91 \pm$ 28.7 hours in cases reduced by BE versus $42.7 \pm 65.8$ hours in children treated by operative reduction $(\mathrm{P}=0.02)$. The symptom length in failed BE was $38.25 \pm 73.3$ hours, there was no significant difference in mean of symptom length between failed and reduced $\mathrm{BE}$ cases $(\mathrm{P}=0.09)$.

The mean age of children with intussusception was $19.57 \pm 19.43$ months in the first episode and it was $20.25 \pm$ 20.4 months in boys and $18.47 \pm 17.7$ in girls $(\mathrm{P}=0.49)$; patients less than one year old comprised $48.9 \%$ at the time of the first episode (Figure 2). Age of recurrent cases at initial onset of intussusception ranged from 3 months to 6.8 years (18.74 \pm 15.3 months) and non-recurrent group was $19.72 \pm 20.1$, the median age between two groups showed no significant difference $(\mathrm{P}=0.77)$.

Intussusception occurred in males more than in females (62.3\% vs. $37.7 \%, \mathrm{P}>0.0001)$ and male to female ratio was 1.65; it indicated an increasing trend from 1.52 in the first year of life to 3.5 in children more than 5 years old (Figure 3). There was no significant difference between recurrence and non-recurrence groups in terms of gender $(\mathrm{P}=0.38)$.

Pathological leading points (PLPs) were observed in $5(2.1 \%)$ children; $2.6 \%$ in recurrence group versus $2 \%$ in non-recurrence group $(\mathrm{P}=0.91)$. Three of these had ileal polyp, the rest were associated with lymphoma and Mackle's diverticulum. The mean age in children with PLPs was $59 \pm 54.5$ versus 18.73 \pm 17.3 months in children without PLPs $(\mathrm{P}=0.08)$. In general, PLPs were less in children aged 3 months to 5 years old compared to the rest of children $(1.4 \%$ vs. $13.3 \%$, respectively, $\mathrm{P}=$ $0.02)$. Seasonal variations of occurrence of intussusception occurred $(\mathrm{P}=0.03)$ more $(59.1 \%)$ in spring and summer. The seasonal distribution did not differ between recurrence and non-recurrence group $(\mathrm{P}=0.56)$. Also there was an association between occurrence intussusception with recent infections such as URI $(\mathrm{P}=0.001)$ and gastroenteritis $(\mathrm{P}=0.001)$ but there was no difference between the two groups in terms of $\mathrm{URI}(\mathrm{P}=0.92)$ and gastroenteritis $(\mathrm{P}=0.64)$.

Table 1. Interval Time and Recurrence of Intussusception Based on the Medical Procedures Performed in Recurrent Episodes

\begin{tabular}{lccc}
\hline Variables & \multicolumn{3}{c}{ Time Interval, d } \\
\cline { 2 - 4 } & $\mathbf{< 1}$ & Between 1-30 & $>\mathbf{3 0}$ \\
\hline Barium enema & 19 & 8 & 19 \\
Operative reduction & 0 & 0 & 8 \\
Spontaneous reduction & 0 & 0 & 3 \\
\hline
\end{tabular}

A

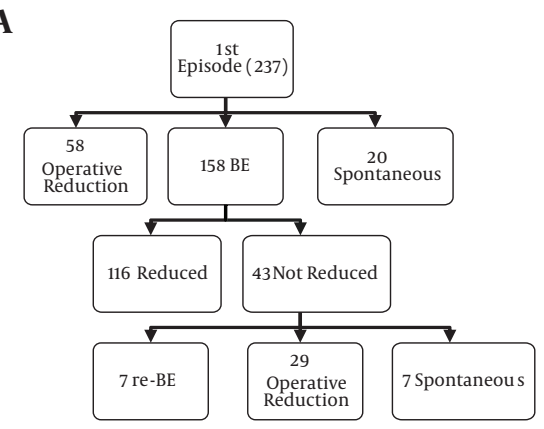

B

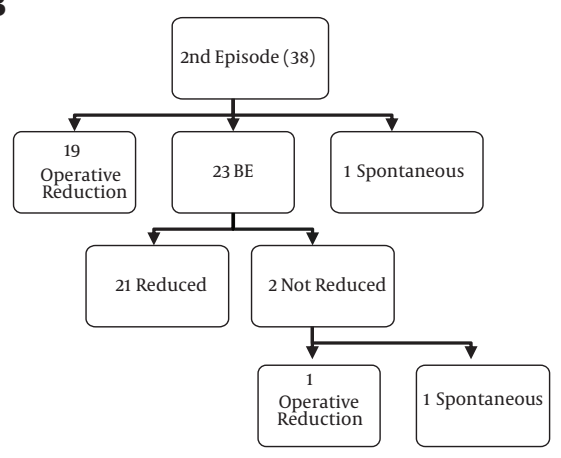

C

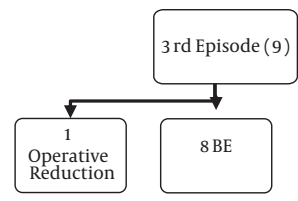

D

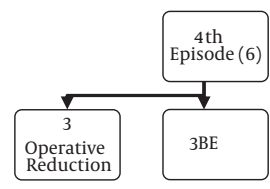

Figure 1. Outcomes in Four First Episodes of Intussusception 


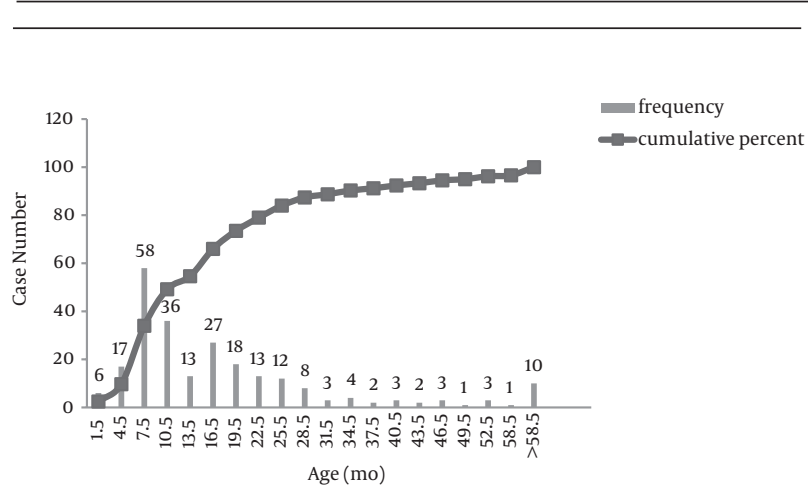

Figure 2. Number of Intussusception Cases by Age

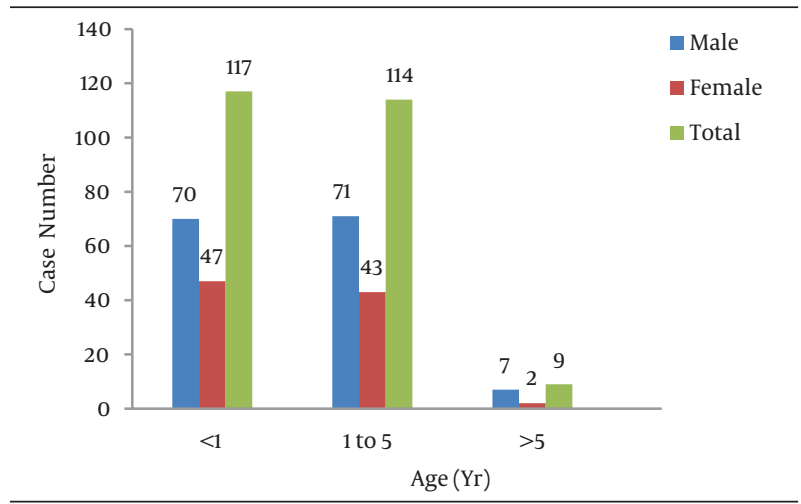

Figure 3. Frequency of Intussusception in Different Age Groups and Sex at The First Episode

\begin{tabular}{|c|c|c|c|c|}
\hline \multirow[t]{2}{*}{ Authors } & \multirow[t]{2}{*}{ Country } & \multicolumn{3}{|c|}{ Recurrence Rate, \% } \\
\hline & & BE & $\mathbf{A E}$ & Operative \\
\hline Beasley et al. (28) & Australia & 18.4 & NA & 2.7 \\
\hline Stringer and Ein (24) & Canada & 11 & 8 & NA \\
\hline Palder et al. (19) & Canada & 10 & 4 & 0 \\
\hline Fecteau et al. (11) & Canada & 12.5 & NA & 8.2 \\
\hline $\operatorname{Ein}(23)$ & Canada & 11 & NA & 3 \\
\hline Eshel et al. (17) & Israel & 10 & 5.9 & 0 \\
\hline Alehossein and Babaheidarian (29) & Iran & 0 & 11 & 2.3 \\
\hline Fragoso et al. (30) & Portugal & NA & 6.5 & 0 \\
\hline Kaiser et al. (31) & India & 13 & NA & 1 \\
\hline Gilmore et al. (32) & Canada & 12.5 & NA & NA \\
\hline Niramis et al. (10) & Thailand & 15.8 & 11.4 & 3 \\
\hline Ksia et al. (18) & Tunisia & 5.7 & NA & 4.6 \\
\hline Our study & Iran & 25.4 & NA & 4.5 \\
\hline
\end{tabular}

\section{Discussion}

For a successful and suitable management of childhood intussusception, it is important to recognize intussusception pattern and recurrent episodes as a sequel after the first intussusception plus its risk factors, so this study has been carried out for the first time involving the highest number of Iranian children with intussusception.

In our study, recurrence rate of intussusception was $16 \%$. It seems recurrence rate was slightly high because some reports noted the overall incidence with $8 \%$ to $15 \%$ (14-17). Ksia et al. reported a total rate of $2 \%$ to $20 \%$ (18). The difference of recurrence rate could be due to the method of calculation, because in some studies, the recurrence rate was calculated as a percentage of the recurrent cases (15, 17,19-22), or the percentage of the recurrent episodes from the total subjects (10). The recurrence rate of intussusception was $10 \%$ to $15 \%$ after non-operative reduction $(12,15,16$, 23,24 ) and 0 to $4 \%$ after operative reduction (25). Table 2 shows recurrence rates in several studies. The rate of recur- rent intussusception can be related to higher failure after $\mathrm{BE}$ in our study than in some other studies as well as the lack of access to air enema (AE) because $\mathrm{AE}$ is more (84\%) effective (26) and the use of $\mathrm{AE}$ is associated with lower recurrence than $\operatorname{BE}(15,24,27,28)$. Also, perhaps the absence of skilled pediatric radiologist at the time of reduction in some cases led to high recurrence rate.

Epidemiologic studies found the risk of recurrence to be lower in children receiving operative reduction than nonoperative reduction $(10,20)$. This is in agreement with our study. It is possible that adhesion created in intestines to surrounding tissues with operative reduction reduced recurrence of intussusception $(10,20)$. We found recurrence rate was high in children 2 to 3-years-old of age than in other age groups. Our findings that 1 ) children 2 to 3 years old had fewer surgery, 2) surgical reduction was more common in children less than one year old had lower recurrence rate, explains the high rate of recurrence in this group. 
In the present study, there were 5 (2.08\%) cases with PLPs that was relatively low. Cases had intestinal polyp and lymphoma as well as Mackle's diverticulum. PLPs are observed in $25 \%$ of patients in all age groups (children and adults) (3) and $1.5 \%$ to $12 \%$ of children with intussusception $(15,26)$. PLPs are more common in infants less than 3 months old and children over 5-years-old (3). In current study only $5.6 \%$ of cases were in this age group. This can be a reasonable cause for the low rate of PLPs. We observed a case with PLPs in recurrent group, he had 4 episodes, three recurred after BE and the last one after surgery. Although previous studies showed $19 \%$ of children with two or more episodes and $4 \%$ of the children without recurrence (3), 9.3\% of recurrent group and $3.8 \%$ of non-recurrent group had PLPs (10) but data from a retrospective review showed no recurrence occurred because of PLPs (18), in agreement with our results. Hsu et al. found that the rate of PLPs was $2.2 \%(15 / 686)$ and all were diagnosed in the first episode and children more than 5 years old were at the highest risk of presence of PLPs (21). So despite presence of PLPs that were observed in recurrence of in tussusception, it may occur in idiopathic intussusception too (3). Our data suggested PLPs were more common in older children ( $>5$-years-old) and not associated with recurrence. Thus we agree with the demand that each recurrence should be managed as the first episode and operative reduction should be considered for failure of non-operative reduction, suspected presence of PLPs, and peritonitis signs $(3,10,18,20)$. In a series, common PLPs were Meckel diverticulum, intestinal polyp, small bowel lymphoma, and duplication cysts (3) and in another report intestinal polyp and Meckel diverticulum (10) that is consistent with our study.

Our success rate by BE was $72.7 \%$. The published rates of success enema reduction vary widely in the literature. The average of successful enemas is $75 \%$. A report presented success rate of $80-95 \%$ after non-operative reduction, on the other hand, rates from $46 \%$ to $63.6 \%$ are reported in some published literature $(10,31,32)$. One reason for this low success rate may be related to delay in presentation to a tertiary pediatric care. Our data showed duration of symptoms was lower in children reduced by BE than in others. The higher symptom length was, the higher likelihood of BE failure and operative intervention was. It is suggested that AE may be better for the patients with duration of symptoms over 24 hours (31). Unfortunately we did not have access to AE. We found, in agreement with some studies, a slight predominance of intussusception in male gender, with male to female ratio of 1.3-2 to 1, rising gradually by age $(2,3,20,33)$. Chen et al. (20) believed intussusception manifested later in boys than in girls and the difference in onset time between the two genders may explain the male dominance. In our study, although the mean age in the initial onset of intussusception was higher in boys, the difference was not significant. Thus, the exact reason for gender difference remains unclear.

Our study showed that the frequency of intussuscep- tion increased rapidly after the first three months of life and its increase continued up to 30 months. After this period, a plateau pattern was observed in the frequency of intussusception. These findings are in agreement with epidemiological studies in Taiwan, Switzerland and Phoenix $(20,25,34)$. In our study, nearly $50 \%$ of children with recurrence of intussusception were younger than one year at the first episode and it decreased to $7.9 \%$ in older children. 71\% of recurrences developed within 6 months of the initial onset, thus it can be concluded that intussusception is more common in the first year of life and the recurrence of intussusception decreases after the toddler period, that is consistent with some other studies $(10,25,33,35,36)$. There were controversies about seasonal variation of the occurrence of intussusception. Our findings showed seasonality of intussusception but had no effect on the recurrence of intussusception. Several studies found no seasonality of intussusception $(25,33$, $36,37)$ while some reported seasonal variation $(20,35)$. Some noted that viral triggers such as viral gastroenteritis, viral illness (URI, flu-like symptoms) may induce intussusception (3) and younger children may have greater exposure to these factors, or be more sensitive to them.

The recurrence of intussusception was related to the method of reduction, as it was more in those children treated by BE than operative reduction. The majority of recurrences were idiopathic. Recurrent intussusceptions were not associated with PLPs; consequently, medical intervention for recurrent intussusception should be similar to the first episode and initially managed by nonoperative reduction.

\section{Acknowledgments}

We would like to thank Dr. Evangeline Foronda for editorial assistance and Dr. Ali Bijani for supporting statistical analysis.

\section{References}

1. Kong FT, Liu WY, Tang YM, Zhong L, Wang XJ, Yang G, et al. Intussusception in infants younger than 3 months: a single center's experience. World J Pediatr. 2010;6(1):55-9. doi:10.1007/s12519-0100007-4. [PubMed: 20143212]

2. Blanch AJ, Perel SB, Acworth JP. Paediatric intussusception: epidemiology and outcome. Emerg Med Australas. 2007;19(1):45-50. doi:10.1111/j.1742-6723.2007.00923.x. [PubMed: 17305660]

3. Kitagawa S MM. Intussusception in children. Up to date on line. kids health wa; 2014. Available from: http://kidshealthwa.com/guidelines/intussusception/.

4. Edino ST, Ochicha O, Mohammed AZ, Anumah M. Intussusception in Kano: a 5-year analysis of pattern, morbidity and mortality. Niger J Med. 2003;12(4):221-4. [PubMed:14768198]

5. Stringer MD, Pablot SM, Brereton RJ. Paediatric intussusception BrJ Surg. 1992;79(9):867-76. [PubMed:1422744]

6. Linke F, Eble F, Berger S. Postoperative intussusception in childhood. Pediatr Surg Int. 1998;14(3):175-7. doi: 10.1007| s003830050479. [PubMed: 9880741]

7. Komadina R, Smrkolj V. Intussusception after blunt abdominal trauma. J Trauma. 1998;45(3):615-6. [PubMed: 9751561]

8. Carneiro PM, Kisusi DM. Intussusception in children seen at Muhimbili National Hospital, Dar es Salaam. East Afr Med J. 2004;81(9):439-42. [PubMed:15626051] 
9. Kuremu RT. Childhood intussusception at the Moi teaching and Referral Hospital Eldoret: management challenges in a rural setting. East Afr Med J. 2004;81(9):443-6. [PubMed:15626052]

10. Niramis R, Watanatittan S, Kruatrachue A, Anuntkosol M, Buranakitjaroen V, Rattanasuwan T, et al. Management of recurrent intussusception: nonoperative or operative reduction? J Pediatr Surg. 2010;45(11):2175-80. doi: 10.1016/j.jpedsurg.2010.07.029. [PubMed: 21034940]

11. Fecteau A, Flageole H, Nguyen LT, Laberge JM, Shaw KS, Guttman FM. Recurrent intussusception: safe use of hydrostatic enema. $J$ Pediatr Surg. 1996;31(6):859-61. [PubMed: 8783124]

12. Soper RT, Brown MJ. Recurrent Acute Intussusception in Children. Arch Surg. 1964;89:188-98. [PubMed:14148764]

13. Herman BE, Becker J. Recurrent acute intussusception--a survey. Surg Clin North Am. 1960;40:1009-18. [PubMed:14401263]

14. Eklof O, Reiter S. Recurrent intussusception. Analysis of a series treated with hydrostatic reduction. Acta Radiol Diagn (Stockh). 1978;19(1B):250-8. [PubMed: 654950]

15. Daneman A, Alton DJ, Lobo E, Gravett J, Kim P, Ein SH. Patterns of recurrence of intussusception in children: a 17-year review. Pediatr Radiol. 1998;28(12):913-9. doi: 10.1007/s002470050497. [PubMed: 9880629]

16. Champoux AN, Del Beccaro MA, Nazar-Stewart V. Recurrent intussusception. Risks and features. Arch Pediatr Adolesc Med. 1994;148(5):474-8. [PubMed: 8180637]

17. Eshel G, Barr J, Heiman E, Bistritzer T, Broide E, Klin B, et al. Incidence of recurrent intussusception following barium versus air enema. Acta Paediatr. 1997;86(5):545-6. [PubMed: 9183497]

18. Ksia A, Mosbahi S, Brahim MB, Sahnoun L, Haggui B, Youssef SB, et al. Recurrent intussusception in children and infants. Afr Paediatr Surg. 2013;10(4):299-301. doi: 10.4103/0189-6725.125414. [PubMed: 24469476]

19. Palder SB, Ein SH, Stringer DA, Alton D. Intussusception: barium or air? J Pediatr Surg. 1991;26(3):271-4. [PubMed: 2030472]

20. Chen SC, Wang JD, Hsu HY, Leong MM, Tok TS, Chin YY. Epidemiology of childhood intussusception and determinants of recurrence and operation: analysis of national health insurance data between 1998 and 2007 in Taiwan. Pediatr Neonatol. 2010;51(5):285-91. doi:10.1016/S1875-9572(10)60055-1. [PubMed: 20951359]

21. Hsu WL, Lee HC, Yeung CY, Chan WT, Jiang CB, Sheu JC, et al. Recurrent Intussusception: when Should Surgical Intervention be performed? Pediatr Neonatol. 2012;53(5):300-3. doi: 10.1016/j.pedneo.2012.07.004. [PubMed:23084722]

22. Justice FA, Nguyen LT, Tran SN, Kirkwood CD, Thi NT, Carlin JB, et al. Recurrent intussusception in infants. J Paediatr Child Health. 2011;47(11):802-5. doi: 10.1111/j.1440-1754.2011.02029.x. [PubMed: 21435072]

23. Ein H. Recurrent intussusception in children. J Ped Surg. 1975;10(5):751-5. doi:10.1016/0 022-3468(75)90380-2.
24. Stringer DA, Ein SH. Pneumatic reduction: advantages, risks and indications. Pediatr Radiol. 1990;20(6):475-7. [PubMed: 2392368]

25. Buettcher M, Baer G, Bonhoeffer J, Schaad UB, Heininger U. Threeyear surveillance of intussusception in children in Switzerland. Pediatrics. 2007;120(3):473-80. doi: 10.1542/peds.2007-0035. [PubMed: 17766518$]$

26. Waseem M, Rosenberg HK. Intussusception. Pediatr Emerg Care. 2008;24(11):793-800. doi: 10.1097/PEC.0b013e31818c2a3e. [PubMed:19018227]

27. Liu KW, MacCarthy J, Guiney EJ, Fitzgerald RJ. Intussusception-current trends in management. Arch Dis Child. 1986;61(1):75-7. [PubMed: 3954422]

28. Beasley SW, Auldist AW, Stokes KB. Recurrent intussusception: barium or surgery? Aust N Z J Surg. 1987;57(1):11-4. [PubMed: 3472505]

29. Alehossein M, Babaheidarian P, Salamati P. Comparison of different modalities for reducing childhood intussusception Iran J Radiol. 2011;8(2):83-7. [PubMed: 23329922]

30. Fragoso AC, Campos M, Tavares C, Costa-Pereira A, Estevao-Costa J. Pneumatic reduction of childhood intussusception. Is prediction of failure important? J Pediatr Surg. 2007;42(9):1504-8. doi: 10.1016/j.jpedsurg.2007.04.013. [PubMed: 17848239]

31. Kaiser AD, Applegate KE, Ladd AP. Current success in the treatment of intussusception in children. Surgery. 2007;142(4):46975. doi:10.1016/j.surg.2007.07.015. [PubMed:17950338]

32. Gilmore AW, Reed M, Tenenbein M. Management of childhood intussusception after reduction by enema. Am J Emerg Med. 2011;29(9):1136-40. doi: 10.1016/j.ajem.2010.08.009. [PubMed: 20980119]

33. Boudville IC, Phua KB, Quak SH, Lee BW, Han HH, Verstraeten T, et al. The epidemiology of paediatric intussusception in Singapore: 1997 to 2004. Ann Acad Med Singapore. 2006;35(10):674-9. [PubMed:17102889]

34. Mandeville K, Chien M, Willyerd FA, Mandell G, Hostetler MA, Bulloch B. Intussusception: clinical presentations and imaging characteristics. Pediatr Emerg Care. 2012;28(9):842-4. doi:10.1097| PEC.0b013e318267a75e. [PubMed: 22929138]

35. Chalya PL, Kayange NM, Chandika AB. Childhood intussusceptions at a tertiary care hospital in northwestern Tanzania: a diagnostic and therapeutic challenge in resource-limited setting. Ital J Pediatr. 2014;40(1):28. doi: 10.1186/1824-7288-40-28. [PubMed: 24618338]

36. Awasthi S, Agarwal GG, Mishra V, Nag VL, El Sayed HF, da Cunha AJ, et al. Four-country surveillance of intestinal intussusception and diarrhoea in children.J Paediatr Child Health. 2009;45(3):826. doi:10.1111/j.1440-1754.2008.01434.x. [PubMed:19210606]

37. Justice F, Carlin J, Bines J. Changing epidemiology of intussusception in Australia. J Paediatr Child Health. 2005;41(9-10):475-8. doi:10.1111/j.1440-1754.2005.00686.x. [PubMed: 16150 062] 